Subclinical endocrinological disease

Series editor: Dr FWF Elte, Department of Internal Medicine, Sint Franciscus Gasthuis, Rotterdam, The Netherlands

\title{
Subclinical thyroid disease
}

\author{
Jan Willem F Elte, Aart H Mudde, Arie C Nieuwenhuijzen Kruseman
}

\section{Summary}

Thyroid disease can roughly be divided into functional and anatomical disorders. Subclinical disease is by definition not accompanied by symptoms or signs and usually goes unrecognized for the bearer (and the observer).

In this communication an overview will be given of existing literature and some own results concerning subclinical hypothyroidism, subclinical thyrotoxicosis and thyroid incidentalomas. Apart from definitions, data on prevalence, clinical effects, prognostic significance and the need for and response to therapy will be discussed.

Keywords: thyroid disease, subclinical hypothyroidism, subclinical hyperthyroidism, thyroid incidentaloma

\section{Department of Internal Medicine, Sint Franciscus Gasthuis, 3045 PM Rotterdam, The Netherlands JWF Elte}

\section{Department of Internal Medicine, Slingeland Ziekenhuis, Doetinchem, The Netherlands \\ AH Mudde}

Department of Internal Medicine, Division of Endocrinology, University Hospital, Maastricht, The Netherlands AC Nieuwenhuijzen Kruseman

\section{Subclinical hypothyroidism}

DEFINITION

Subclinical hypothyroidism is defined by the finding of a raised thyrotropin level in combination with normal thyroid hormone levels in an asymptomatic patient. ${ }^{1}$ This disorder may occur in the natural history of Hashimoto's thyroiditis and after treatment of hyperthyroidism by either surgery or iodine-131. Many other terms have been used in the past to describe this condition, such as preclinical hypothyroidism, asymptomatic thyroiditis and decreased thyroid reserve. This reflects the controversy as to whether the disorder represents a mild form of hypothyroidism ${ }^{2}$ or is merely a biochemical abnormality. ${ }^{1}$ In order to make a decision whether or not subclinical hypothyroidism should be treated, it is indeed important to know whether the disorder has any adverse effects and/or how often overt hypothyroidism will develop. Relevant literature data are discussed below.

\section{PREVALENCE}

The prevalence of subclinical hypothyroidism varies from $5.0 \%$ to $13.2 \%$, depending on the populations studied. ${ }^{3-5}$ Women appear to be affected more than twice as often as men. Serum thyrotropin levels are usually only slightly elevated (between 4 and $10 \mathrm{mU} / \mathrm{l}$ ). With higher thyrotropin levels, the prevalence of antithyroid antibodies is more frequent ${ }^{3} ; 80 \%$ of patients with thyrotropin levels above $10 \mathrm{mU} / 1$ and $60 \%$ with a thyrotropin level between 6 and $10 \mathrm{mU} / 1$ have auto-antibodies. ${ }^{3}$

\section{PROGNOSTIC SIGNIFICANCE}

Most of the follow-up studies have dealt with patients with (symptomless) autoimmune thyroiditis. ${ }^{6,7}$ Tunbridge $e t$ al ${ }^{6}$ selected 163 people from the original Wickham survey having either antithyroid antibodies and/or raised thyrotropin $(6-10 \mathrm{mU} / \mathrm{l})$ concentrations in the absence of overt or treated thyroid disease. Reassessment took place after two and four years. It appeared that the annual incidence of overt hypothyroidism was $2.5 \%$ for men with thyroid antibodies and raised thyrotropin. For women these figures were $0.4 \%$ for those with antithyroid antibodies but a normal initial thyrotropin and $5.0 \%$ for those with both antibodies and initially increased thyrotropin. None of the patients with increased thyrotropin but no antithyroid antibodies and no control subjects become hypothyroid during the follow-up period. ${ }^{6}$ Gordin and Lamberg ${ }^{7}$ have reported even higher figures in a small group of 22 patients with symptomless autoimmune thyroiditis. The annual incidence of hypothyroidism was $7.3 \%$ in those with only antithyroid antibodies and $26 \%$ in those with antibodies and increased thyrotropin levels $(<1 \%$ in the general population). In contrast Engler $e t a l^{\beta}$ have reported the results of a follow-up study in which mainly the degree of the thyrotropin increase determined the incidence of overt hypothyroidism. If thyrotropin were $6 \mathrm{mU} / 1,9.7 \%$ developed hypothyroidism after five years, compared with $16.6 \%$ in subjects with a thyrotropin of $12 \mathrm{mU} / 1$ and $32.6 \%$ in subjects with a thyrotropin of $20 \mathrm{mU} / 1$. No differences were observed with regard to the initial antibody status, the cause of subclinical hypothyroidism or clinical parameters of thyroid hormone action. ${ }^{8}$ However, in combination with thyrotropin the initial antithyroid antibody status and the thyroidal triiodothyronine reserve had predictive value. ${ }^{8}$ Rosenthal $e t a l^{5}$ followed 26 older patients with serum thyrotropin $>4 \mathrm{mU} / 1$ for four years and noted that one third developed biochemical thyroid failure. All patients with initial thyrotropin levels above $20 \mathrm{mU} / 1$ and $80 \%$ of those with high-titer thyroid antimicrosomal antibodies developed overt hypothyroidism. ${ }^{5}$

In a recent study of 30 patients, $\mathrm{Kabadi}^{9}$ reported the existence of two 
biochemically identical populations of patients with subclinical hypothyroidism: a) true subclinical hypothyroidism with known aetiologic factors, and $b$ ) euthyroidism with reset thyrostat - a permanent state without progression to hypothyroidism, probably secondary to subtle insults to the thyroid.

\section{PERIPHERAL EFFECTS AND RESULTS OF TREATMENT}

One important reason to screen and treat patients with subclinical hypothyroidism would be the occurrence of clinically manifest effects which improve on therapy. Over the years, many such studies have been reported. These have revealed, however, inconsistent results, especially with regard to the relation of thyrotropin and ischaemic heart disease. Also, most of these studies were uncontrolled and open with small numbers of patients. Moreover, many of the markers of peripheral thyroid hormone action are too insensitive to show changes in subtle thyroid function abnormalities, which may be an explanation for the inconsistent results. Ridgway et $a l^{2}$ reported high-normal systolic time interval measurements in patients with a mean thyrotropin of $28 \mathrm{mU} / 1$ (range 4.5-117), which correlated with both serum thyrotropin and L-thyroxine levels and decreased after L-thyroxine therapy. The systolic time interval was found to improve after therapy in the group of patients with the most abnormal baseline values only, whereas no correlation with pre-ejection period/left ventricular ejection time (PEP/LVET ratio) was found with thyrotropin. ${ }^{10}$ In patients with subclinical hypothyroidism and in control subjects the systolic time interval was similar, although a decreased left ventricular ejection fraction and other subtle effects on left ventricular function after exercise were observed in the patients with subclinical hypothyroidism. ${ }^{11,12}$ As a consequence of this controversy, contradictory advice has been given with regard to the justification of thyroid hormone therapy. ${ }^{11,12}$

Abnormal lipid profiles in subclinical hypothyroidism resulting in an increased risk for cardiovascular disease may be another reason for intervention. Again, contradictory results have been reported. Most authors have found normal values for serum total cholesterol, high density lipoprotein (HDL)cholesterol and triglycerides ${ }^{2,10,11,13}$ or even low serum cholesterol in patients with thyroid antibodies ${ }^{14}$ and no significant change after therapy. ${ }^{2,10,11}$ However, Staub et $\mathrm{al}^{13}$ have observed increased low density lipoprotein (LDL)-cholesterol levels in their group with the highest thyrotropin levels $(>12 \mathrm{mU} / \mathrm{l})$. Althaus et al ${ }^{15}$ found a similar effect on LDL-concentration and also decreased HDLcholesterol levels, whereas Caron et $a l^{16}$ only described decreased HDLcholesterol levels, which increased after L-thyroxine therapy. An increased relative risk for coronary heart disease has only been shown by Tieche et al $^{14}$ in women with thyrotropin $>4 \mathrm{mU} / 1$. In this study, however, serum cholesterol levels were unexpectedly low.

Haggerty et $a l^{17}$ found an increased lifetime prevalence of major depression in women with subclinical hypothyroidism $(56 \%)$ compared with euthyroid subjects $(20 \%)(p<0.05)$. Moreover, psychometric testing improved during L-thyroxine therapy in a double-blind cross-over study in 17 randomly selected women with subclinical hypothyroidism identified in a population study. ${ }^{18}$

Other abnormal peripheral effects reported are: lengthening of the ankle reflex time,${ }^{1}$ improving after therapy ${ }^{13}$; elevated serum myoglobulin levels ${ }^{13}$; increased serum prolactin levels, especially after thyrotropin-releasing hormone, ${ }^{10,13,19}$ normalising after therapy. ${ }^{10}$ Moreover, in patients with menorrhagia, ${ }^{20}$ infertility $^{19}$ and peripheral arterial disease, ${ }^{21}$ a significant number of patients have been found with subclinical hypothyroidism. Thyroid hormone therapy in subclinical hypothyroidism may relieve menorrhagia ${ }^{20}$ and ovarian function disturbance. ${ }^{21}$ So it appears that multiple, albeit sometimes slight, peripheral effects may be observed in subclinical hypothyroidism, which often improve after thyroid hormone treatment.

\section{SCREENING}

Although the effectiveness of screening in the general adult population, both in terms of costs and health benefits, may be doubtful, ${ }^{6,22}$ it has been suggested that it is worthwhile in selected populations, such as women over $40-50$ years of age..$^{22,23}$

\section{CLINICAL CONSEQUENCES}

The finding of a serum thyrotropin $>10-12 \mathrm{mU} / 1$, especially if accompanied by positive antithyroid antibodies, seems to be a significant risk factor for overt disease $^{5,6,21}$ and is in our opinion a reason for $\mathrm{L}$-thyroxine treatment. For the other patients with subclinical hypothyroidism only follow-up is indicated (reset thyrostat or incipient hypothyroidism). ${ }^{9}$ 


\section{Subclinical thyrotoxicosis}

\section{DEFINITION}

Subclinical thyrotoxicosis has been defined as an asymptomatic condition with an absent or impaired response of thyrotropin to thyrotropin-releasing hormone in the presence of normal serum levels of thyroid hormones for the general population, though supra-optimal for the individual. ${ }^{24}$ The condition may arise exogenously, most frequently as a consequence of $\mathrm{L}$-thyroxine treatment or endogenously, mostly in multinodular goitre. The functional state of thyroid autonomy is identical with endogenous subclinical thyrotoxicosis. ${ }^{25}$

Recent studies have indicated that the pituitary - thyroid setpoint is uniquely differently defined between individuals. ${ }^{26}$ In this concept the serum thyrotropinlevel, as a 'thermostate', more reliably indicates the level of thyroid activity in target tissues than the level of serum thyroid hormones do, especially in the high-normal range of thyroid hormone concentrations.

\section{DIAGNOSIS AND PREVALENCE}

The wide availability of sensitive immunometric thyrotropin assays in the past decade has revealed that a substantial number of subjects on thyroid replacement therapy are substituted to a level of thyrotropin suppression. ${ }^{27}$ When measured with one of these so-called 'second' and 'third' generation thyrotropin assays it appears that even in the low range the basal serum thyrotropin level is highly predictive for the outcome of thyrotropin-releasing hormone testing. ${ }^{28} \mathrm{~A}$ suppressed basal serum thyrotropin level $(<0.1 \mathrm{mU} / 1)$ in the presence of normal serum thyroid hormone levels is highly indicative of subclinical thyrotoxicosis, although this may be misleading in several conditions like major non-thyroidal illness, hypothalamic pituitary disease or during treatment with drugs like corticosteroids or anti-epileptics. ${ }^{27}$

The prevalence of endogenous subclinical thyrotoxicosis is highly dependent on the population studied; it appears to be highest in nodular goitrous disease. ${ }^{29}$ There is evidence that thyroid function in multinodular goitre tends to increase in concert with an increase in nodularity with aging. ${ }^{30}$ Transition from euthyroidism via subclinical thyrotoxicosis to overt thyrotoxicosis in multinodular goitre has been observed. ${ }^{31}$ On the other hand spontaneous regression to normal thyrotropin levels in subjects with suppressed thyrotropin at initial testing has also been described. ${ }^{32}$ As a consequence of the natural history of multinodular goitre the prevalence of subclinical thyrotoxicosis, which may last for many years, is higher in elderly than in younger subjects with goitrous disease. ${ }^{29}$ The overall prevalence of subclinical thyrotoxicosis in nodular goitre is estimated at about $20 \%{ }^{24,30}$ The condition is much more frequent in women than in men.

\section{PERIPHERAL EFFECTS}

Apart from indications of increased tissue thyroid activity, expressed by elevations of serum parameters like sex hormone binding globulin ${ }^{33}$ most attention has been drawn to the possible effects of subclinical thyrotoxicosis on the skeletal and cardiovascular systems.

\section{The skeletal system}

An increase of bone turnover is a well recognised phenomenon of overt thyrotoxicosis. The availability of more sensitive parameters of bone turnover and more sophisticated ways to determine bone mineral density has given impetus to research on bone metabolism in subclinical thyrotoxicosis. The available data on this topic are mainly derived from cross-sectional studies and are largely confined to women. The results are not unequivocal. Several studies in L-thyroxine-treated subjects have reported a stimulated osteoblastic function as estimated by elevated serum levels of serum osteocalcin ${ }^{34,35}$ as well as an increased osteoclastic activity, represented by increased urinary excretion of pyridinium cross links. ${ }^{36}$ These data contrast to other studies in which no increase in bone turnover in exogenous subclinical thyrotoxicosis could be substantiated, as estimated by normal alkaline phosphatase and osteocalcin levels. ${ }^{37-39}$ Surveys on bone mineral density in subclinical thyrotoxicosis have given discrepant results as well. There are many confounding factors which may have biased these studies. For instance, the aetiology of the initial thyroid disease may be of crucial importance for the outcome of bone mineral density measurements in cross-sectional studies. Excluding subjects with previous thyrotoxicosis resulted in a loss of statistical significance of the observed decrease in bone mineral density in subclinical thyrotoxic subjects in two studies. ${ }^{40,41} \mathrm{By}$ doing so, however, a type- 2 error may have been introduced, since the remaining study population could have been too small. Inclusion of some subjects who have 


\begin{tabular}{|l|}
\hline Subclinical thyrotoxicosis \\
\hline - decreased thyrotropin, normal \\
L-thyroxine, triiodothyronine, no \\
complaints; \\
- exogenously caused by L-thyroxine \\
treatment \\
- endogenous prevalence up to $20 \%$ \\
in multinodular goitre \\
- increased risk for atrial fibrillation, \\
slightly increased bone turnover \\
and decreased bone mineral density \\
in postmenopausal women \\
- antithyroid treatment might be \\
indicated in endogenous subclinical \\
thyrotoxicosis associated with atrial \\
fibrillation, but is not standard \\
practice
\end{tabular}

had clearly elevated thyroid hormone levels of some time during treatment with L-thyroxine could have overestimated the negative impact on bone mass in some studies. ${ }^{42}$ While inclusion of subjects with non-suppressed thyrotropin levels could have underscored the effect of L-thyroxine treatment on bone mineral density in others. ${ }^{37,43}$ Calcitonin deficiency in subjects who underwent total thyroidectomy because of thyroid cancer might theoretically result in excessive bone loss apart from the effect of thyrotropin suppression. ${ }^{34,44}$ This hypothesis, however, has not been substantiated. ${ }^{43}$ Although in more recently published studies on bone mineral density in subclinical thyrotoxicosis confounding factors have been eliminated more carefully, the results are still conflicting..$^{35,38}$

Menopausal status may be a critical factor in the extent to which subclinical thyrotoxicosis may be harmful to bone. ${ }^{45}$ In a recently published meta-analysis of 13 cross-sectional studies, a negative impact on bone mass of exogenous subclinical thyrotoxicosis could indeed only be substantiated in postmenopausal women. ${ }^{46}$

In endogenous subclinical thyrotoxicosis data are scanty. Mudde et al ${ }^{47}$ described a reduced forearm bone mineral density in a group of predominantly postmenopausal women with subclinical thyrotoxic multinodular goitre. In contrast, Faber and Galløe ${ }^{46}$ could not substantiate a difference in bone mass in premenopausal women, while Földes $e t a l^{48}$ have reported a decreased bone mineral density in postmenopausal women with solitary, autonomously functioning, thyroid nodules but not in premenopausal women.

In conclusion, the available data suggest that bone mineral density in both exogenous and endogenous subclinical thyrotoxicosis may be slightly decreased in postmenopausal women. The data in premenopausal women and in men are either too conflicting or too scanty to make definite conclusions at this stage.

\section{The heart}

Several studies have indicated decreased PEP/LVET ratios in thyrotropin suppressive treatment. ${ }^{49,50}$ An increased basal heart rhythm has been found in subjects with endogenous subclinical thyrotoxic multinodular goitre. ${ }^{51}$ It has been recognised for many years that subclinical thyrotoxicosis might be the underlying condition in atrial fibrillation..$^{52}$ Conversely a prevalence of atrial fibrillation of up to $28 \%$ in endogenous subclinical hyperthyroidism has been documented. ${ }^{29}$ Echocardiographically documented left ventricular wall hypertrophy, which might be an independent predictor of cardiac morbidity, has been reported in exogenous subclinical thyrotoxicosis. ${ }^{53}$

A transverse study by Leese $e t a b^{4}$ has shown an increased incidence of ischaemic heart disease in subjects under the age of 65 years on L-thyroxine treatment. The risk, however, was not different between those with suppressed and normal thyrotropin levels.

\section{Clinical consequences}

During life, the thyroid hormonal level within one individual is remarkably stable. There is a log-linear relationship between serum thyrotropin and thyroid hormone concentrations. ${ }^{26} \mathrm{~A}$ small increase in thyroid hormonal level may result in suppression of thyrotropin while the thyroid hormones are still within the transverse reference range. ${ }^{26}$ This situation seems to represent a very early stage of thyrotoxicosis. The clinical consequences of the subtle changes in tissue metabolism caused by this slight thyroid hormone excess, however, have yet to be established.

Although there is cumulative evidence suggesting a slight decrease in bone mineral density caused by subclinical thyrotoxicosis, especially in postmenopausal women, we are not aware of studies indicating an increased fracture incidence in affected subjects. If thyrotropin suppression is the goal of treatment, as it is in the management of differentiated thyroid cancer, adjuvant bisphosphonate treatment has been proposed. ${ }^{55}$ There is preliminary evidence that accelerated bone loss is prevented by antithyroid treatment of endogenous subclinical thyrotoxicosis. ${ }^{56}$ Considering the lack of evidence for an increased fracture risk in subclinical thyrotoxicosis, these treatment modalities should not be generally advised at this stage. An indication for antithyroid treatment of subclinical thyrotoxicosis might be represented by atrial fibrillation, but this is not standard practice at the present time. ${ }^{57}$

\section{Thyroid incidentalomas}

\section{PREVALENCE}

The prevalence of thyroid nodules and goitres is highly geographically dependent, especially in relation to iodine status. In iodine-sufficient areas, thyroid nodules may be found in $4-7 \%$ of the adult population. ${ }^{3,58}$ The main reason for 


\begin{tabular}{|l|}
\hline Thyroid incidentalomas \\
\hline - incidentally found thyroid nodules \\
in otherwise healthy persons, \\
usually diagnosed by ultrasound \\
- prevalence up to $40 \%$, mostly in \\
females and right-sided \\
- no screening, follow-up \\
investigations or therapy warranted \\
\hline
\end{tabular}

1 Evered DC, Ormston BJ, Smith PA, Hall R, Bird T. Grades of hypothyroidism. BMf 1973 1: 657-62.

2 Ridgway EC, Cooper DS, Walker H, Rodbard $D$, Maloof F. Peripheral responses to thyroid hormone before and after L-thyroxine therapy in patients with subclinical hypothyroidism. Clin Endocrinol Metab 1981; 53: 1238-42.

3 Tunbridge WMG, Evered DC, Hall R, et al. The spectrum of thyroid disease in a community: the Wickham survey. Clin Endocrinol 1977; 7: 481-93.

4 Sawin CT, Castelli WP, Hershman JM McNamara P, Bacharach P. The aging thyroid. Thyroid deficiency in the Framingham Study. Thyroid deficiency in the Framingham

5 Rosenthal MJ, Hunt WC, Garry PJ, Goodwin JS. Thyroid failure in the elderly. Microsoma antibodies as discriminant for therapy. $\mathfrak{F} A M A$ 1987; 258: 209-13.

6 Tunbridge WMG, Brewis M, French JM, et al. Natural history of autoimmune thyroiditis. $B M \mathcal{F}$ 1981; 282: 258-62.

7 Gordin A, Lamberg BA. Spontaneous hypothyroidism in symptomless autoimmune thyroiditis. A long-term follow-up study. Clin Endocrinol 1981; 15: 537-43.

8 Engler H, Staub J-J, Althaus B, Ryff A, Viollier E, Girard J. Follow-up of 120 patients with E, Girard J. Follow-up of 120 patients with subclinical hypothyroidism over more than 10 years: risk factors for overt disease analyzed by life-table analysis. In: Gordon A, Gross $\mathrm{J}$, Hennemann G, eds. Progress in thyroid res

9 Kabadi UM. Subclinical hypothyroidism. Natural course of the syndrome during a prolonged follow-up study. Arch Intern Med 1993; 153: 957-61.

detecting thyroid nodules is the risk for thyroid cancer which has been reported to be as high as $4.1-17 \%$ in women and $8.2-13 \%$ in men with dominant thyroid nodules, versus $4.1-13 \%$ in patients with multiple nodules. ${ }^{59,60}$ In iodinedeficient areas approximately half as many patients with nodular thyroid abnormalities have carcinomas $(2.7 \%)$ compared with patients from iodinesufficient areas $(5.3 \%){ }^{59}$

It has long been known that occult thyroid nodules may be found in approximately $50 \%$ of unselected autopsies ${ }^{61,62}$ and operatively removed thyroid glands from patients with hyperthyroidism. ${ }^{61}$ At autopsy, occult cancer is detected in $4.2 \%$ of nodular glands and $2.1 \%$ of clinically normal glands. ${ }^{62}$ Moreover, it appears that many of the thyroid nodules are dynamic and changeable in form and function; a decrease and even disappearance after years of follow-up is not rare. ${ }^{63}$

\section{ULTRASONOGRAPHY}

With the advent of ultrasonography as the most sensitive method of investigation of the thyroid gland, thyroid nodules have been shown to be much more common than is evident by palpation only. ${ }^{64-68}$ Incidental small and asymptomatic thyroid nodules or incidentalomas were found in $13.4 \%$ of patients undergoing 'duplex' imaging of the extracranial carotid arteries, ${ }^{64}$ in $40 \%$ of patients with hyperparathyroidism ( $88 \%$ detected by ultrasonography), ${ }^{65}$ and in $25 \%$ of patients who underwent abdominal ultrasonography. ${ }^{66}$

In an unselected population from Finland ${ }^{67}$ unsuspected thyroid abnormalities were found in $27.3 \%$ of patients by ultrasonography. Of the 69 subjects with echo abnormalities, 39 had solitary nodules, 15 multiple nodules and 15 a diffuse abnormality. ${ }^{67}$ Only $5.1 \%$ of 253 subjects had abnormal palpatory findings. Most of the focal echo abnormalities were small; $71 \%$ were less than $1 \mathrm{~cm}$ in diameter. Fine needle aspiration was performed in 30 subjects with nodular lesions; no unequivocal malignancies were observed. ${ }^{67}$ In a prospective study to examine the prevalence of thyroid nodules in 100 asymptomatic subjects, palpable nodules were identified in 21 subjects (nine solitary and 12 multiple) ${ }^{68}$ In contrast, 67 subjects had abnormal ultrasound findings (22 solitary and 45 multiple). Nodules were found more frequently in women (72\%) than in men $(41 \%)$. Concordance rate between ultrasound and palpatory findings was $49 \%{ }^{68}$

\section{CLINICAL CONSEQUENCES}

Considering the high prevalence of thyroid incidentalomas and the usually benign course, a conservative approach is advised. Neither screening, nor follow-up or any therapeutic intervention seems to be warranted in subjects with this kind of abnormality. ${ }^{67,68}$

10 Cooper DS, Halpern R, Wood LC, Levin AA, Ridgway EC. L-Thyroxine therapy in subclinical hypothyroidism. Ann Intern Med 1984; 101 $18-24$

11 Bell GM, Todd WTA, Forfar JC, et al. Endorgan responses to thyroxine therapy in subclinical hypothyroidism. Clin Endocrinol 1985; 22: 83-9.

12 Forfar JC, Wathen CG, Todd WTA, et al. Left ventricular performance in subclinical ventricular performance in subclinical
hypothyroidism. $Q f M$ Med $1985 ; 224: 857-65$.

13 Staub J-J, Althaus BU, Engler H, et al. Spectrum of subclinical and overt hypothyroidism effect on thyrotropin, prolactin, and thyroid reserve, and metabolic impact on peripheral target tissues. Am ₹ Med 1992; 92: 631-42.

14 Tièche M, Lupi GA, Gutzwiller F, Grob PJ Studer H, Bürgi H. Borderline low thyroid function and thyroid autoimmunity. Risk factors for coronary heart disease? Br Heart $¥ 1981$; 46: $202-6$.

15 Althaus BU, Staub J-J, Ryff-de Lèche A, Oberhänsli A, Stähelin HB. LDL/HDLchanges in subclinical hypothyroidism: possible risk factors for coronary heart disease. Clin risk factors for coronary heart
Endocrinol 1988; 28: 157-63.

16 Caron Ph, Calazel C, Parr HJ, Hoff M, Louve JP. Decreased HDL cholesterol in subclinical hypothyroidism: the effect of $\mathrm{L}$-thyroxine hypothyroidism: the effect of L-thyro
therapy. Clin Endocrinol 1990; 33: 519-23.

17 Haggerty JJ, Stern RA, Mason GA, Beckwith J, Morey CE, Prange AJ. Subclinical hypothyrodism: a modifiable risk factor for depression? Am $\mathcal{F}$ Psychiatry 1993; 150: 508-10.
18 Nyström E, Caidahl K, Fager G, Wikkelsö C, Lundberg P-A, Lindstedt $G$. A double-blind cross-over 12-month study of L-thyroxine treatment of women with 'subclinical' hypothyroidism. Clin Endocrinol 1988; 29: 63-76.

19 Bispink L, Brändle W, Lindner C, Bettendorf G. Präklinische Hypothyreose und Ovarialfunktionsstörungen. Geburtshilfe Frauenheilk 1989; 49: 881-8.

20 Wilansky DL, Greisman B. Early hypothyroidism in patients with menorrhagia. Am F Obstet Gynecol 1989; 160: 673-7.

21 Powell J, Alaghband Zadeh J, Carter G, Greenhalgh RM, Fowler PBS. Raised serum thyrotrophin in women with peripheral arterial disease. Br f Surg 1987; 74: 1139-41.

22 Helfand M, Crapo LM. Screening for thyroid disease. Ann Intern Med 1990; 112: 840-9.

23 Riniker $M$, Tièche M, Lupi GA, Grob P, Studer , Büri $H$ Prevalence of various P, Studer , Burgi hypothyroidism among patients of a general medical department. Clin Endocrinol 1981; 14: $69-74$

Hall R, Evered DC, Tunbridge WMG. The role of TSH and TRH in thyroid disease. In: Walker $\mathrm{G}$, ed. Ninth symposium of advanced medicine. London: Pitman Medical, 1973; pp 15-26.

25 Elte JWF, Haak A, Wiarda KS, et al. Propranolol improves the impaired TSH response to TRH in patients with autonomously functioning euthyroid multinodular goitre. Clin Endocrinol 1982; 16: 553-63. 
26 Spencer CA, LoPresti JS, Patel A, et al. AppAetric thyrotropin assay to subnormal measurement. F Clin Endocrinol Metab 1990; 70: 453-60.

27 Ross DS, Daniels GH, Gouveia D. The use and limitations of a chemiluminescent thyrotropin assay as a single thyroid function test in an out-patient endocrine clinic. $\mathcal{F}$ Clin Endocrinol Metab 1990; 71: 764-9.

28 Seth J, Kellett HA, Caldwell G, et al. A sensitive immunoradiometric assay for serum thyroid stimulating hormone; a replacement for the thyrotrophin releasing hormone test? $B M \mathcal{F}$ 1984; 289: 1334-6.

29 Tenerz $\AA$, Forberg $R$, Jansson $R$. Is a more active attitude warranted in patients with subactive attitude warranted in patients with sub-
clinical thyrotoxicosis? $₹$ Intern Med 1990; 228: 229-33.

30 Rieu M, Bekka S, Sambor B, Borrod JL, Fombeur JP. Prevalence of subclinical hyperthyroidism and relationship between thyroid hormonal status and thyroid ultrasonographic parameters in patients with non-toxic nodular goitre. Clin Endocrinol 1993; 39: 67-71.

31 Elte JWF, Bussemaker JK, Haak A. The natural history of euthyroid multinodular goitre. Postgrad Med f 1990; 66: 186-90.

32 Parle JV, Franklyn JA, Cross KW, Jones SC, Sheppard MC. Prevalence and follow-up of abnormal thyrotropin (TSH) concentrations in the elderly in the United Kingdom. Clin Endocrinol 1991; 34: 77-83.

33 Faber J, Perrild H, Johansen JS. Bone gla protein and sex hormone-binding globulin in nontoxic goitre: parameters for metabolic status nontoxic goitre: parameters for metabolic status
at the tissue level. $₹$ Clin Endocrinol Metab 1990; at the tissue $49-55$.

34 Diamond T, Nery L, Hales I. A therapeutic dilemma: suppressive doses of thyroxine significantly reduce bone mineral measurements in both premenopausal and postmenopausal women with thyroid carcinoma. $\mathcal{f}$ Clin Endocrinol Metab 1990; 72: 1184-8.

35 Kung AWC, Lorentz Th, Tan SCF. Thyroxine suppressive therapy decreases bone mineral density in postmenopausal women. Clin Endocrinol 1993; 39: 535-40.

36 Harvey RD, McHardy KC, Reid IW, et al. Measurement of bone collagen degradation in hyperthyroidism and during thyroxine replacement therapy using pyridinium crosslinks as ment therapy using pyridinium crosslinks as specific urinary markers.
Metab 1991; 72: 1189-94.

37 Franklyn JA, Betteridge J, Daykin J, et al. Long-term thyroxine treatment and bone mineral density. Lancet 1992; II: 9-13.

38 Grant DJ, McMurdo ET, Mole PA, Paterson CR, Davies RR. Suppressed TSH levels secondary to thyroxine replacement therapy are not associated with osteoporosis. Clin Endocrinol 1993; 39: 529-33.

39 Ross DS, Ardisson LJ, Nussbaum SR, Meskell MJ. Serum osteocalcin in patients taking Lthyroxine who have subclinical hyperthyroidism. $f$ Clin Endocrinol Metab 1991; 72: 507-9.
40 Greenspan SL, Greenspan FS, Resnick NM, Frielarder AL, Genant HK. Skeletal integrity in premenopausal and postmenopausal women receiving long-term L-thyroxine therapy. $A m \mathcal{F}$ Med 1991; 91: 5-14

41 Adlin EV, Maurer AH, Marks AD, Channick BJ. Bone mineral density in postmenopausal women treated with L-thyroxine. $A m \widetilde{F} M e d$ 1991; 90: 360-6.

42 Ross DS, Neer RM, Ridgway EC, Daniels GH Subclinical hyperthyroidism and reduced bone density as a possible result of prolonged suppression of the pituitary-thyroid axis with Lpression of the pituitary-thyroid axis $\mathrm{Am} \mathcal{\mathrm { J }}$ Med 1987; 82: 1167-70.

43 Hurley DL, Tiegs RD, Wahner HW, Heath III H. Axial and appendicular bone mineral density in patients with long-term deficiency or excess of calcitonin. $N$ Engl $f$ Med 1987; 317: 537-41.

44 Gonzalez DC, Mautalen CA, Correa PH, Tame EE, Tamer SE. Bone mass in totally thyroidectomized patients. Role of calcitonin deficiency and exogenous thyroid treatment. Acta Endocrinol 1991; 124: 521-5.

45 Campos-Pastor MM, Munoz-Torres $M$, Escobar-Jiménez $F$, Ruiz de Almodóva $M$, Jódar Gimeno E. Bone mass in females with different thyroid disorders: influence of menopausal status. Bone Miner 1993; 21 : 1-8.

46 Faber J, Galløe AM. Changes in bone mas during prolonged subclinical hyperthyroidism during prolonged subclinical hyperthyroidism due to L-thyroxine treatment: a meta-

47 Mudde AH, Reijnders FJL, Nieuwenhuijzen Kruseman AC. Peripheral bone density in women with untreated multinodular goitre. $\mathrm{Clin}$ Endocrinol 1992; 37: 35-9.

48 Földes J, Farján G, Szathmari M, Varga F Krasznai I, Horvath C. Bone mineral density in patients with endogenous subclinical hyperthyroidism; is the thyroid status a risk factor for osteoporosis? Clin Endocrinol 1993; 39: 521-7.

49 Jennings PE, O'Malley BP, Griffin KE, Northover B, Rosenthal FD. Relevance of increased serum thyroxine concentrations associated with normal serum triiodothyronine values in hypothyroid patients receiving thyroxine: a case for 'tissue thyrotoxicosis'. $B M F$ 1984; 289; 1645-7.

50 Tseng KH, Walfish PG, Persaud JA, Gilbert BW. Concurrent aortic and mitral valve echocardiography permits measurement of systolic time intervals as an index of peripheral tissue thyroid function status. $\mathcal{f}$ Clin Endocrinol Metab 1989; 69: 633-8.

51 Boutin JM, Matte R, D'Amour P, et al. Characteristics of patients with normal T 3 and $T 4$ and low TSH response to TRH. Clin Endocrino 1986; 25: 579-88.

52 Forfar JC, Miller HC, Toft AD. Occult thyrotoxicosis: a correctable cause of 'idiopathic' atrial fibrillation. $A m$ 于 Cardiol 1979; 44: 9-12.

53 Biondi B, Fazio S, Carella C, et al. Cardiac effects of long term thyrotropin-suppressive therapy with Levothyroxine. $\mathcal{f}$ Clin Endocrinol therapy with Levothyroxin
54 Leese GP, Jung RT, Guthrie C, Waugh N. Brouning MCK. Morbidity in patients on $\mathrm{L}$ thyroxine: a comparison of those with normal TSH to those with suppressed TSH. Clin Endocrinol 1992; 37: 500-3.

55 Rosen HN, Moses AC, Gundberg C, et al. Therapy with parenteral pamidronate prevents thyroid hormone-induced bone turnover in humans. F Clin Endocrinol Metab 1993; 77 664-9.

56 Mudde AH, Houben AJHM, Nieuwenhuijzen Kruseman AC. Bone metabolism during antithyroid drug treatment of endogenous subclinical hyperthyroidism. Clin Endocrinol 1994; 41: 421-4.

57 Forfar JC, Feek CM, Miller HC, Toft AD. Atrial fibrillation and isolated suppression of the pituitary-thyroid axis: response to specific antithyroid therapy. Int $\mathcal{F}$ Cardiol $1981 ; 1: 43-8$.

8 Rojeski MT, Gharib H. Nodular thyroid disease. $N$ Engl F Med 1985; 313: 428-36.

59 Belfiore A, La Rosa DG, La Porta GA, et al. Cancer risk in patients with cold thyroid nodules: relevance of iodine intake, sex, age, and multinodularity. Am f Med 1992: 93: 363-9.

60 McCall A, Jarosz H, Lawrence AM, Paloyan E. The incidence of thyroid carcinoma in solitary cold nodules and in multinodular goiters. Surgery 1986; 100: 1128-32.

61 Rice CO. Incidence of nodules in the thyroid. A comparative study of symptomless thyroid glands removed at autopsy and hyperfunctionglands removed at autopsy and hyperfunctioning goiters operative

62 Mortensen JD, Woolner LB, Bennett WA Gross and microscopic findings in clinically normal thyroid glands. $f$ Clin Endocrinol Metab 1955; 15: 1270-80.

63 Rallison ML, Dobyns BM, Meikle AW, Bishop $M$, Lyon JL, Stevens W. Natural history of thyroid abnormalities: prevalence, incidence, and regression of thyroid diseases in adolescents and young adults. Am f Med 1991; 91: 363-70.

64 Carroll BA. Asymptomatic thyroid nodules: incidental sonographic detection. $A \mathcal{F}$ 1982; 133: 499-501.

65 Stark DD, Clark OH, Gooding GAW, Moss AA. High-resolution ultrasonography and comAA. High-resolution ultrasonography and computed tomography of thyroid lesions in patients 863-8.

66 Woestyn J, Afschrift M, Schelstraete K, Vermeulen A. Demonstration of nodules in the normal thyroid by echography. $\mathrm{Br} \mathcal{F}$ Radiol 1985; 58: 1179-82.

67 Brander A, Viikinkoski P, Nickels J, Kivisaari L. Thyroid gland: US screening in a random adult population. Radiology 1991; 181: 683-7.

68 Ezzat S, Sarti DA, Cain DR, Braunstein GD. Thyroid incidentalomas. Prevalence by palpation and ultrasonography. Arch Intern Med 1994; 154: 1838-40. 